\title{
The TGFB1 gene is associated with curve severity but not with the development of adolescent idiopathic scoliosis: a replication study in the Chinese population
}

\author{
Leilei Xu, Weixiang Sun, Xiaodong Qin, Yong Qiu and Zezhang Zhu*
}

\begin{abstract}
Background: The transforming growth factor beta-1 (TGFB1) gene was recently reported to be a new susceptible gene of adolescent idiopathic scoliosis (AIS) in Russian population. This study aimed to replicate the relationship between the TGFB1 gene and the susceptibility of AIS in a Chinese population, and to further describe its association with the curve severity.

Methods: A total of 1251 female AIS patients and 994 age-matched healthy controls were included in this study. The rs1800469 of TGFB1 gene was genotyped for all participants using the PCR-based Invader assay. The differences of genotype and allele distributions between AIS patients and healthy controls were assessed using the Chi-square test. One-way ANOVA test was used to compare the mean Cobb angles among patients with different genotypes.

Results: There was no significant difference in terms of the genotype and the allele frequency between the patients and the controls. The mean Cobb angle was $34.7 \pm 11.9^{\circ}$ (range 25-61\%). Case-only analysis showed that rs1800469 was significantly associated with the curve severity. Patients with genotype $\Pi$ had remarkably higher curve magnitude $\left(39.1 \pm 12.8^{\circ}\right)$ than those with genotype $C T\left(34.8 \pm 11.1^{\circ}\right)$ or CC $\left(32.1 \pm 10.6^{\circ}\right)$.

Conclusions: The TGFB1 gene may not be a predisposition gene of AIS in the Chinese population. However, it can play a role in the curve progression of AIS. Replication studies in other ethnic groups are warranted to understand the implication of TGFB1 gene in AIS.
\end{abstract}

Keywords: Adolescent idiopathic scoliosis, TGFB1, Polymorphism, Replication

\section{Background}

Adolescent idiopathic scoliosis is a structural curvature of the spine that affects millions of children in the world [1-3]. Although numerous studies have been performed to investigate the etiology of AIS, there was still a limited understanding of its pathogenesis [4-7]. As a complex multi-factorial disease, AIS was believed to be resulted from the interaction among multiple genetic loci as well as environmental factors [8, 9]. Through genetic linkage analysis, a few susceptible loci have been proposed to be closely related to AIS [10-12]. Subsequently, more predisposition genes of AIS were

\footnotetext{
* Correspondence: zhuzezhang@126.com

Department of Spine Surgery, The Affiliated Drum Tower Hospital of Nanjing

University Medical School, Zhongshan Road 321, Nanjing 210008, China
}

identified through association studies, including estrogen receptor 1 (ESR1) [13, 14], estrogen receptor 2 (ESR2) [15], matrilin 1 (MATN1) [16], melatonin receptor 1B (MTNR1B) [17], tryptophan hydroxylase 1 (TPH1) [18], interleukin-6 (IL-6) [19, 20], C17orf67 and DOT1L [21]. In recent years, the pathogenesis of AIS was further investigated through genome-wide association studies (GWASs). Sharma et al. [22] reported a strong association between the CHL1 gene and AIS in 419 white families. GWAS in Japanese population confirmed that the ladybird homeobox 1 (LBX1) gene and G protein-coupled receptor 126 (GPR126) gene were significantly associated with the development of AIS $[23,24]$. Specifically, the LBX1 gene was confirmed as 
the susceptibility gene of AIS by a large-scale study in the European population [25].

Although the genetic background of AIS has been investigated extensively through genetic association study, spurious results may be produced along with those intriguing findings. As a well established AIS susceptibility gene in the Caucasian population, the CHL1 gene failed to be replicated in the Chinese Han population [26]. The ESR1 gene was firstly confirmed to be associated with AIS in the Japanese population and later successfully validated in the Chinese and the Caucasian population $[13,14,27,28]$. Interestingly, this association was not supported by other 3 replication studies separately performed in the Asian and the Caucasian population [29-31]. Takahashi et al. [30, 32] failed to validate previously reported susceptible genes of AIS in the Japanese population, including ESR2, MTNR1B, TPH1 and MATN1. Collectively, there exists a significant divergence between the Asian and the Caucasian populations regarding the association of susceptible genes with the pathogenesis of AIS. Moreover, this divergence can even exist in the same population. Therefore, the large-scale replication study is warranted to validate previously reported susceptible genes of AIS.

Recently, Ryzhkov et al. [33] reported that the genetic polymorphism of the transforming growth factor beta-1 (TGFB1) gene was significantly associated with the onset of AIS as well as the curve severity in the Russian population. Interestingly, mutations in TGFB family genes can lead to syndromic forms of scoliosis such as Marfan and Loeys Dietz Syndrome [34, 35]. It is therefore possible that common variants of TGFB1 can be associated with AIS through similar pathway. To our knowledge, there is still a lack of knowledge concerning the association of TGFB1 gene with AIS in the Chinese population. The primary purpose of this study was to replicate the relationship between the TGFB1 gene and the susceptibility of AIS in the Chinese population, and to further describe its association with the curve severity.

\section{Methods}

\section{Patients}

Under the approval of Ethics Committee of The Affiliated Drum Tower Hospital of Nanjing University Medical School, this case-control study recruited 1251 female AIS patients and 994 age-matched healthy female subjects who underwent the routine examination prior to the college admission. All the patients were diagnosed as AIS through clinical and radiological examinations during their visits to our center for the treatment. $\mathrm{Pa}$ tients were excluded from this study if having scoliosis secondary to known etiology, including congenital scoliosis, neuromuscular scoliosis, scoliosis secondary to skeletal dysplasia, and connective tissue abnormalities.
The healthy subjects were confirmed through Adam's Forward Bend Test by an experienced spinal surgeon (Q.Y.). All participants were from Chinese Han population living along Yangtze River.

To investigate the association between the target SNP and the curve severity, a subgroup of patients were included in the case-only study according to the following inclusion criteria: 1 . having no history of brace treatment or any other conservative treatment for scoliosis; 2 . either reaching skeletal maturity or undergoing fusion surgery due to curve progression. Patients were considered to have reached skeletal maturity if aged more than 16 years or having a Risser sign of 5 . The curve severity was recorded as the Cobb angle measured at the latest visit after skeletal maturity for non-operated patients, or at the last visit before surgery for those undergoing surgery. Patients with Cobb angle more than $40^{\circ}$ were assigned to the progressive curve group, and those with Cobb angle between 20 and $30^{\circ}$ were assigned to nonprogressive curve group. To investigate the association between the target SNP and the age of onset of AIS, all patients and their parents were queried on the chronological age when they initially noticed the deformity, which was recorded as the age of onset for each patient if accurately provided.

\section{Genotyping of the target SNP}

Blood samples were collected for DNA analysis, with informed consent obtained from the participants. Genomic DNA was extracted from blood leukocytes by standard protocols (Qiagen K.K., Tokyo, Japan). The rs1800469 of the TGFB1 gene was genotyped using TaqMan SNP Genotyping Assay according to the manufacturer's instructions, which was read with an ABI PRISM 7900HT sequence detection system (Applied Biosystems, Foster City, CA). Samples with ambiguous results were collected in the 96-well plate and later genotyped for precise results. Twenty percent of the samples were selected randomly to validate the reproducibility of the genotyping results.

\section{Statistical analysis}

The Hardy-Weinberg equilibrium (HWE) test was used for both the patient and the control group. The differences of genotype and allele distributions between AIS patients and healthy controls were assessed using the Chi-square test. In addition, the Chi-square test was also used to compare the allele frequency between patients with progressive curve and those with non-progressive curve. The odds ratio (OR) was calculated using the minor allele as a reference. The One-way ANOVA test was used to compare the mean Cobb angles of different genotypes in case-only analyses. Similarly, the age of 
onset was also compared among different genotypes using the One-way ANOVA test. The SPSS software (version 17.0, Chicago, IL) was used for statistical analyses. Statistical significance was set at a $p$ value of less than 0.05 .

\section{Results}

\section{Case-control association analysis}

The rs1800469 was successfully genotyped for all patients and controls. The concordance rate was $100 \%$ for samples genotyped in duplicate. No significant difference of genotype frequencies from the HWE test was noted in the patients $(p=0.13)$ or the normal controls $(p=0.10)$. As shown in Table 1, neither the genotype nor the allele frequency of the rs1800469 was significantly different between the patients and the controls.

\section{Case-only association analysis}

According to the inclusion criteria for the case-only association analysis, a subgroup of 746 patients were investigated to determine the association of the rs1800469 with the curve severity, among whom 349 had received fusion surgery, and the other 397 had been observed until skeletal maturity. The mean Cobb angle was $34.7 \pm 11.9^{\circ}\left(\right.$ range $\left.25-61^{\circ}\right)$. As shown in Table 2, the rs1800469 was found to be associated with the curve severity. Patients with genotype TT had remarkably higher curve magnitude $\left(39.1 \pm 12.8^{\circ}\right)$ than those with genotype $\mathrm{CT}\left(34.8 \pm 11.1^{\circ}\right)$ or $\mathrm{CC}\left(32.1 \pm 10.6^{\circ}\right)$. Moreover, the progressive curve group was found to have significantly higher frequency of allele $\mathrm{T}$ than the non-progressive curve group (34.2 \% vs. $28.5 \%$, $p<0.05)$.

Another subgroup of 535 patients were investigated to determine the association of the rs1800469 with the age of onset of AIS. The mean age of onset was $11.4 \pm 1.8$ years (range 10.3-14.4 years). As shown in Table 3, no significant association was found between the rs1800469 and the age of onset.

Table 1 Results of association analysis for the rs1800469 in 1251 cases and 994 controls

\begin{tabular}{lllll}
\hline & $\begin{array}{l}\text { Patients } \\
(n=1251)\end{array}$ & $\begin{array}{l}\text { Controls } \\
(n=994)\end{array}$ & $p$ value & $\begin{array}{l}\text { Odds Ratio }{ }^{a} \\
(95 \% \mathrm{Cl})\end{array}$ \\
\hline Genotype & & & 0.92 & N/A \\
$\mathrm{CC}$ & 592 & 479 & & \\
$\mathrm{CT}$ & 520 & 406 & & \\
$T$ & 139 & 109 & & \\
Alleles & & & 0.72 & $1.02(0.93-1.11)$ \\
$\mathrm{C}$ & 1704 & 1364 & & \\
$\top$ & 798 & 624 & & \\
\hline
\end{tabular}

$N / A$ indicates not available

${ }^{a}$ Odds ratio was calculated with the minor allele $\mathrm{T}$ as reference allele
Table 2 Results of case-only analysis of the curve severity

\begin{tabular}{llcl}
\hline Genotype & Number & Curve severity (degrees) & $p$ value \\
\hline CC & 347 & $32.1 \pm 10.6$ & $<0.01$ \\
CT & 314 & $34.8 \pm 11.1$ & \\
$\Pi T$ & 85 & $39.1 \pm 12.8$ & \\
\hline
\end{tabular}

\section{Discussion}

Genetic association study is a widely applied strategy to determine the genetic variants associated with AIS $[13,15-18,21]$. The most important step of genetic association study is to target the putative candidate gene that could be implicated in the pathogenesis of the disease. The TGFB1 is a multifunctional cytokine that could affect a variety of physiological processes including cellular proliferation, differentiation and the formation and degradation of extracellular matrix proteins [36]. Previous studies showed a significant difference in TGFB1 expression level between convex and concave side of AIS patients [37]. Moreover, the TGFB1 was found to play a role in the degeneration of intervertebral discs [38]. Herein, the TGFB1 gene could be a highly putative predisposition gene of AIS. In a recent report of Ryzhkov et al. [33], the TGFB1 gene was identified as a new susceptible gene of AIS. In addition, it could also be a modifier gene of AIS, since it was found to be related with the age of onset and the curve severity [33]. However, the role of TGFB1 as a predisposition gene of AIS has not been addressed in the Chinese population. A genetic replication study involving both patients and controls is required to address this issue.

Our results showed that the previously reported association of the rs1800469 with the susceptibility of AIS in the Russian population could not be replicated in the Chinese population. It is a common phenomenon to have a negative replication outcome of variants associated with complex traits. To be noted, there is actually a lack of consensus on most susceptible genes of AIS except for the LBX1 gene [26, 29, 30, 32, 39, 40]. The discrepancy may be resulted from the ethnic differences between the different populations or from a lack of statistical power. In the study of Ryzhkov et al. [33], only 300 cases and 300 controls were recruited for the association analysis. Moreover, the genotype frequency of the

Table 3 Results of case-only analysis of the age of onset

\begin{tabular}{llcl}
\hline Genotype & Number & Age of onset (years) & $p$ value \\
\hline CC & 263 & $11.2 \pm 1.3$ & 0.78 \\
CT & 217 & $11.7 \pm 1.2$ & \\
$\Pi T$ & 55 & $11.6 \pm 1.4$ & \\
\hline
\end{tabular}


rs1800469 in the patients did not follow HWE test, which could hamper the reliability of their conclusion [33]. In this study, we included a cohort of patients and controls with much larger sample size to detect the effect sizes as shown in the study of Ryzhkov et al. [33]. Therefore, it was unlikely for the current replication to have false-negative association due to a lack of statistical power. Collectively, our data did not support the clinical application of this gene as a predisposition gene of AIS in the Chinese population.

Relationships between the TGFB1 gene and the curve severity and age of onset of AIS were also analyzed in the current study. We found that allele $\mathrm{T}$ and genotype TT of the rs1800469 was significantly associated with progressive curve of AIS. Previous studies have reported that allele $\mathrm{T}$ and genotype TT of the rs1800469 were associated with increased plasma levels of TGFB1 [41, 42]. Besides, an abnormally higher expression of TGFB1 in articular process cartilages was detected at the concave side of AIS as compared with the convex side [43]. Therefore, we speculated that the different expression of TGFB1 between the concave and convex side of AIS could be implicated in the progression of the curve. Although the TGFB1 gene was reported to be significantly associated with the age of onset [33], such association was not replicated in our analysis. Collectively, it is likely that the TGFB1 gene could be a modifier gene that plays a role in the curve progression of AIS. The functional variants of TGFB1 can be potentially applied to the precise prediction of curve progression in AIS patients and used to guide bracing or surgical treatment. Herein, functional analysis concerning the expression of TGFB1 gene in patients with progressive curve and nonprogressive curve is warranted to explain its relationship with the curve progression.

\section{Conclusion}

Considering the large sample size of the present study and strict inclusion criteria for the case-only analysis, we conclude that the TGFB1 gene may not be a predisposition gene of AIS in the Chinese population. However, the TGFB1 gene is likely to be implicated in the curve progression. Replication studies in other ethnic groups are warranted to understand the implication of the TGFB1 gene in AIS.

\footnotetext{
Abbreviations

AIS: adolescent idiopathic scoliosis; ESR1: estrogen receptor 1; ESR2: estrogen receptor 2; GPR126: G protein-coupled receptor 126; GWAS: genome-wide association studies; IL-6: interleukin-6; LBX1: ladybird homeobox 1; MATN1: matrilin 1; MTNR1B: melatonin receptor 1B; OR: odds ratio; SNPs: single nucleotide polymorphisms; TGFB1: transforming growth factor beta-1; TPH1: tryptophan hydroxylase 1 .
}

\section{Competing interests}

The authors declare no competing interests.

\section{Authors' contributions}

LX performed the study. WS and XQ performed the statistical analysis. ZZ conceived of the study and participated in its design. YQ drafted the manuscript. All authors read and approved the final manuscript.

\section{Acknowledgements}

This work was supported by the National Natural Science Foundation of China (Grant No. 81501849).

Received: 10 June 2015 Accepted: 5 January 2016

Published online: 13 January 2016

\section{References}

1. Weinstein SL. Advances in the diagnosis and management of adolescent idiopathic scoliosis. J Pediatr Orthop. 1994;14:561-3.

2. Lonstein JE. Adolescent idiopathic scoliosis: screening and diagnosis. Instr Course Lect. 1989;38:105-13.

3. Horne JP, Flannery R, Usman S. Adolescent idiopathic scoliosis: diagnosis and management. Am Fam Physician. 2014;89:193-8.

4. Burwell RG, Aujla RK, Kirby AS, Dangerfield PH, Moulton A, Cole AA, et al. Body mass index of girls in health influences menarche and skeletal maturation: a leptin-sympathetic nervous system focus on the trunk with hypothalamic asymmetric dysfunction in the pathogenesis of adolescent idiopathic scoliosis? Stud Health Technol Inform. 2008;140:9-21.

5. Girardo M, Bettini N, Dema E, Cervellati $S$. The role of melatonin in the pathogenesis of adolescent idiopathic scoliosis (AIS). Eur Spine J. 2011;20 Suppl 1:S68-74.

6. Burwell RG, Dangerfield PH. Pathogenesis of progressive adolescent idiopathic scoliosis. Platelet activation and vascular biology in immature vertebrae: an alternative molecular hypothesis. Acta Orthop Belg. 2006;72:247-60.

7. Ahn UM, Ahn NU, Nallamshetty L, Buchowski JM, Rose PS, Miller NH, et al. The etiology of adolescent idiopathic scoliosis. Am J Orthop (Belle Mead NJ). 2002;31:387-95.

8. Miller NH. Cause and natural history of adolescent idiopathic scoliosis. Orthop Clin North Am. 1999;30:343-52.

9. Miller NH, Mims B, Child A, Milewicz DM, Sponseller P, Blanton SH. Genetic analysis of structural elastic fiber and collagen genes in familial adolescent idiopathic scoliosis. J Orthop Res. 1996;14:994-9.

10. Gurnett CA, Alaee F, Bowcock A, Kruse L, Lenke LG, Bridwell KH, et al. Genetic linkage localizes an adolescent idiopathic scoliosis and pectus excavatum gene to chromosome 18 q. Spine (Phila Pa 1976). 2009;34:E94-100.

11. Gao X, Gordon D, Zhang D, Browne R, Helms C, Gillum J, et al. CHD7 gene polymorphisms are associated with susceptibility to idiopathic scoliosis. Am J Hum Genet. 2007;80:957-65.

12. Miller NH, Justice CM, Marosy B, Doheny KF, Pugh E, Zhang J, et al. Identification of candidate regions for familial idiopathic scoliosis. Spine (Phila Pa 1976). 2005;30:1181-7.

13. Wu J, Qiu Y, Zhang L, Sun Q, Qiu X, He Y. Association of estrogen receptor gene polymorphisms with susceptibility to adolescent idiopathic scoliosis. Spine (Phila Pa 1976). 2006;31:1131-6

14. Inoue M, Minami S, Nakata Y, Kitahara H, Otsuka Y, Isobe K, et al. Association between estrogen receptor gene polymorphisms and curve severity of idiopathic scoliosis. Spine (Phila Pa 1976). 2002;27:2357-62.

15. Zhang HQ, Lu SJ, Tang MX, Chen LQ, Liu SH, Guo CF, et al. Association of estrogen receptor beta gene polymorphisms with susceptibility to adolescent idiopathic scoliosis. Spine (Phila Pa 1976). 2009;34:760-4.

16. Chen Z, Tang NL, Cao X, Qiao D, Yi L, Cheng JC, et al. Promoter polymorphism of matrilin-1 gene predisposes to adolescent idiopathic scoliosis in a Chinese population. Eur J Hum Genet. 2009:17:525-32.

17. Qiu XS, Tang NL, Yeung HY, Lee KM, Hung WW, Ng BK, et al. Melatonin receptor 1B (MTNR1B) gene polymorphism is associated with the occurrence of adolescent idiopathic scoliosis. Spine (Phila Pa 1976). 2007;32:1748-53.

18. Wang H, Wu Z, Zhuang Q, Fei Q, Zhang J, Liu Y, et al. Association study of tryptophan hydroxylase 1 and arylalkylamine $\mathrm{N}$-acetyltransferase polymorphisms with adolescent idiopathic scoliosis in Han Chinese. Spine (Phila Pa 1976). 2008;33:2199-203. 
19. Nikolova S, Dikova M, Dikov D, Djerov A, Dzhebir G, Atanasov V, et al. Role of the IL-6 gene in the etiopathogenesis of idiopathic scoliosis. Anal Cell Pathol (Amst). 2015;2015:621893.

20. Aulisa L, Papaleo P, Pola E, Angelini F, Aulisa AG, Tamburrelli FC, et al. Association between IL-6 and MMP-3 gene polymorphisms and adolescent idiopathic scoliosis: a case-control study. Spine (Phila Pa 1976). 2007:32:2700-2.

21. Mao S, Xu L, Zhu Z, Qian B, Qiao J, Yi L, et al. Association between genetic determinants of peak height velocity during puberty and predisposition to adolescent idiopathic scoliosis. Spine (Phila Pa 1976). 2013;38(12):1034-9.

22. Sharma S, Gao X, Londono D, Devroy SE, Mauldin KN, Frankel JT, et al. Genome-wide association studies of adolescent idiopathic scoliosis suggest candidate susceptibility genes. Hum Mol Genet. 2011;20:1456-66.

23. Takahashi Y, Kou I, Takahashi A, Johnson TA, Kono K, Kawakami N, et al. A genome-wide association study identifies common variants near LBX1 associated with adolescent idiopathic scoliosis. Nat Genet. 2011:43:1237-40.

24. Kou I, Takahashi Y, Johnson TA, Takahashi A, Guo L, Dai J, et al. Genetic variants in GPR126 are associated with adolescent idiopathic scoliosis. Nat Genet. 2013;45:676-9

25. Grauers A, Wang J, Einarsdottir E, Simony A, Danielsson A, Akesson K, et al Candidate gene analysis and exome sequencing confirm LBX1 as a susceptibility gene for idiopathic scoliosis. Spine J. 2015;15:2239-46.

26. Qiu XS, Lv F, Zhu ZZ, Qian BP, Wang B, Yu Y, et al. Lack of association between the CHL1 gene and adolescent idiopathic scoliosis susceptibility in Han Chinese: a case-control study. BMC Musculoskelet Disord. 2014;15:38.

27. Nikolova S, Yablanski V, Vlaev E, Stokov L, Savov AS, Kremensky IM. Association between ESR1 common genetic polymorphisms and curve severity of idiopathic scoliosis in Bulgarian patients: A case-control study. C R Acad Bulg Sci. 2015;68:783-8.

28. Nikolova S, Yablanski V, Vlaev E, Getova G, Atanasov V, Stokov L, et al. Alpha gene polymorphisms and susceptibility to idiopathic scoliosis in Bulgarian patients: a Case-control Study. OA Maced J Med Sci. 2015;3:278-82.

29. Tang NL, Yeung HY, Lee KM, Hung WW, Cheung CS, Ng BK, et al. A relook into the association of the estrogen receptor [alpha] gene (Pvull, Xbal) and adolescent idiopathic scoliosis: a study of 540 Chinese cases. Spine (Phila Pa 1976). 2006;31:2463-8.

30. Takahashi Y, Matsumoto M, Karasugi T, Watanabe K, Chiba K, Kawakami N, et al. Replication study of the association between adolescent idiopathic scoliosis and two estrogen receptor genes. J Orthop Res. 2011;29:834-7.

31. Janusz P, Kotwicki T, Andrusiewicz M, Kotwicka M. Xbal and Pvull polymorphisms of estrogen receptor 1 gene in females with idiopathic scoliosis: no association with occurrence or clinical form. PLoS One. 2013;8:e76806.

32. Takahashi Y, Matsumoto M, Karasugi T, Watanabe K, Chiba K, Kawakami N, et al. Lack of association between adolescent idiopathic scoliosis and previously reported single nucleotide polymorphisms in MATN1, MTNR1B, TPH1, and IGF1 in a Japanese population. J Orthop Res. 2011;29:1055-8.

33. Ryzhkov II, Borzilov EE, Churnosov MP, Ataman AP, Dedkov AA, Polonikov AP. Transforming Growth Factor Beta 1 is a Novel Susceptibility Gene for Adolescent Idiopathic Scoliosis. Spine (Phila Pa 1976). 2013;12:E699-704.

34. Rienhoff HJ, Yeo CY, Morissette R, Khrebtukova I, Melnick J, Luo S, et al. A mutation in TGFB3 associated with a syndrome of low muscle mass, growth retardation, distal arthrogryposis and clinical features overlapping with Marfan and Loeys-Dietz syndrome. Am J Med Genet A. 2013;161A:2040-6.

35. Kuechler A, Altmuller J, Nurnberg P, Kotthoff S, Kubisch C, Borck G. Exome sequencing identifies a novel heterozygous TGFB3 mutation in a disorder overlapping with Marfan and Loeys-Dietz syndrome. Mol Cell Probes. 2015 doi:10.1016/j.mcp.2015.07.003.

36. Ingman WV, Robertson SA. The essential roles of TGFB1 in reproduction. Cytokine Growth Factor Rev. 2009;20:233-9.

37. Qiu GX, Guo SJ, Liu Y, Qian WW, Wu ZH. The expression of collagen type I, II and TGF-beta1 in the articular processes of scoliosis patients. Zhonghua Yi Xue Za Zhi. 2005:85:2391-4.

38. Nerlich AG, Bachmeier BE, Boos N. Expression of fibronectin and TGF-beta1 mRNA and protein suggest altered regulation of extracellular matrix in degenerated disc tissue. Eur Spine J. 2005;14:17-26.

39. Jiang H, Qiu X, Dai J, Yan H, Zhu Z, Qian B, et al. Association of rs 11190870 near LBX1 with adolescent idiopathic scoliosis susceptibility in a Han Chinese population. Eur Spine J. 2013;22:282-6.

40. Fan $Y H$, Song $Y Q$, Chan D, Takahashi $Y$, Ikegawa S, Matsumoto $M$, et al. SNP rs11190870 near LBX1 is associated with adolescent idiopathic scoliosis in southern Chinese. J Hum Genet. 2012;57:244-6.
41. Grainger DJ, Heathcote K, Chiano M, Snieder H, Kemp PR, Metcalfe JC, et al. Genetic control of the circulating concentration of transforming growth factor type beta1. Hum Mol Genet. 1999;8:93-7.

42. Silverman ES, Palmer LJ, Subramaniam V, Hallock A, Mathew S, Vallone J, et al. Transforming growth factor-beta1 promoter polymorphism C-509 T is associated with asthma. Am J Respir Crit Care Med. 2004;169:214-9.

43. Xu H, Qiu G, Wu Z, Wang Y, Zhang J, Liu Y, et al. Expression of transforming growth factor and basic fibroblast growth factor and core protein of proteoglycan in human vertebral cartilaginous endplate of adolescent idiopathic scoliosis. Spine (Phila Pa 1976). 2005;30:1973-8.

\section{Submit your next manuscript to BioMed Central and we will help you at every step:}

- We accept pre-submission inquiries

- Our selector tool helps you to find the most relevant journal

- We provide round the clock customer support

- Convenient online submission

- Thorough peer review

- Inclusion in PubMed and all major indexing services

- Maximum visibility for your research

Submit your manuscript at www.biomedcentral.com/submit
) Biomed Central 